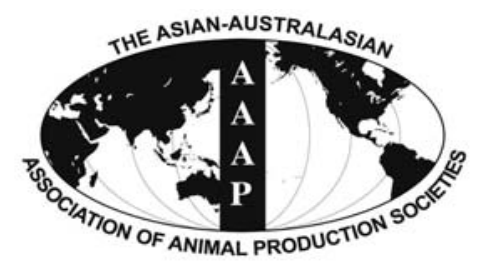

Asian-Aust. J. Anim. Sci.

Vol. 24, No. 2 : 155 - 161

February 2011

www.ajas.info

\title{
Multiple Maternal Lineages of Vietnamese Local Chickens Inferred by Mitochondrial DNA D-loop Sequences
}

\author{
Ngo Thi Kim Cuc ${ }^{1,2}$, Henner Simianer ${ }^{1}$, Linn Fenna Groeneveld ${ }^{2}$ and Steffen Weigend ${ }^{2, *}$ \\ ${ }^{1}$ Department of Animal Sciences, Animal Breeding and Genetics Group, Georg-August-Universität Göttingen, \\ Albrech-Thaer-Weg 3, 37075, Göttingen, Germany \\ ${ }^{2}$ Friedrich Loeffler Institut, Institute of Farm Animal Genetics, Mariensee, 31535, Neustadt, Germany
}

\begin{abstract}
In this study, mitochondrial DNA (mtDNA) sequence polymorphism was used to assess genetic diversity of nine Vietnamese local chicken breeds. In addition, two Chinese breeds kept in Vietnam were included in the analysis for comparison. A 455bp fragment of the mtDNA D-loop region was sequenced in 222 chickens of these 11 breeds. As reference, a skeleton was constructed based on chicken mtDNA sequences taken from the Genbank. Haplotypes of the nine Vietnamese local and two Chinese breeds were aligned together with these sequences. The Vietnamese and Chinese breeds showed a high degree of variability. In total, 37 haplotypes were identified in the chicken breeds studied forming eight clades. Thereby, the majority of individuals of the two Chinese breeds grouped together in one clade which is assumed to have its roots in the Indian subcontinent. Although the Vietnamese chicken breeds were distributed across all eight clades, most of them clustered in three main clades. These results suggest that the Vietnamese domestic chickens have originated from multiple maternal lineages, presumably from Yunnan and adjacent areas in China, South and Southwest China and/or surrounding regions (i.e. Vietnam, Burma, Thailand, and India). (Key Words : Mitochondrial DNA, Vietnamese Local Chickens, Maternal Lineages)
\end{abstract}

\section{INTRODUCTION}

Mitochondrial DNA (mtDNA) is considered a powerful source of molecular information to track the ancestry of breeds back hundreds of generations (Harpending et al., 1998). Different hypotheses about chicken domestication based on mtDNA analyses are found in the literature. Fumihito et al. (1996) suggested a monophyletic origin of domestic chickens from Gallus gallus gallus and that a single domestication event occurred in Thailand and adjacent regions, while Kanginakudru et al. (2008) found evidence for domestication of Indian chickens from Gallus gallus spadiceus and Gallus gallus gallus as well as from Gallus gallus murghi. A study that analyzed BCDO2, a gene encoding an enzyme which converts carotene into its colourless variant, suggested the introgression of the yellow skin gene from Gallus sonneratii into modern chicken breeds (Eriksson et al., 2008). Other reports assumed multiple and independent domestication events in South China, Southeast Asia and the Indian subcontinent (Liu et

\footnotetext{
* Corresponding Author : Steffen Weigend. Tel: +49-5034-871180, Fax: +49-5034-871-143, E-mail: steffen.weigend@fli.bund.de Received April 19, 2010; Accepted August 17, 2010
}

al., 2006 a; Oka et al., 2007). Liu et al. (2006) revealed nine divergent clades (named clades A-I) related to geographical distribution in a wide range of domestic chickens in Eurasian regions. Oka et al. (2007) identified seven clades (named clades A-G) in Japanese chickens of which the four clades A, B, C and E are identical to clades E, A, D and B, respectively, described by Liu et al. (2006).

Vietnam is located in Southeast Asia having a common border of 1,350 km with Southern China (GSO, 2008). Human migration from Southern China to Vietnam enabled introduction of Chinese chickens to Vietnam (Taylor, 1983; Nyiri and Saveliev, 2002). In addition, during recent years some exotic breeds were imported from other countries such as China, France and Germany etc. The most common exotic breeds kept as scavenging chickens are Tam Hoang and Luong Phuong from China. Farmers' preferences for exotic breeds with high performance may have led to introgression of exotic breeds into the Vietnamese gene pool (Tieu et al., 2008). Little is known, however, about the origin and the history of Vietnamese domestic chickens. Some recent studies based on microsatellite markers showed sub-structuring of Vietnamese chickens (Cuc et al., 2010) and a close relationship between the Vietnamese 
chickens of the Ha Giang province (located in the Northwest) with Red Jungle fowl populations (Berthouly et al., 2009). Based on mtDNA analysis, Liu et al. (2006) found the distribution of Vietnamese chicken samples in two different clades. The latter study, however, was based only on a small number $(n=3)$ of Vietnamese chicken samples. The current study aimed to determine the degree of shared maternal mtDNA haplotypes between Vietnamese local chicken breeds, and hence to reveal maternal lineages of origin.

\section{MATERIALS AND METHODS}

\section{Populations and blood sampling}

The study was carried out in nine Vietnamese local chicken breeds. These breeds are located in eight different districts in four agro-ecological zones from both the southern and northern parts of Vietnam (Table 1). These areas were reported as areas of origin or current distribution of the populations under study (Su et al., 2004). The Ho breed is kept in only one village (Ho Village) in the Red River Delta in the North, whereas the Ri and Tau Vang breeds are raised in almost every household in the North and the South, respectively. Two breeds, Dong Tao and Mia, are kept in the Red River Delta. The Te chickens are assumed to carry a dwarf gene. However, information on the distribution of these chickens in Vietnam is not available. The Choi chickens are game birds reared at many places across the country. The Ac and H'mong chickens, kept in the South and North, respectively, are used for making traditional tonics to treat old or sick people (Su et al., 2004). Vietnamese local populations were collected from field flocks. In these populations there was no breeding program implemented so that there was no exchange of breeding chickens. Identification of each individual Vietnamese chicken was based on its phenotypic
Table S1. Haplotype names and accession numbers of chicken mtDNA sequences used in this study

\begin{tabular}{|c|c|c|}
\hline $\begin{array}{l}\text { Haplotype } \\
\text { name }\end{array}$ & $\begin{array}{c}\text { Accession } \\
\text { number }\end{array}$ & Reference \\
\hline A1 -A9 & & This study \\
\hline B1- B8 & & This study \\
\hline $\mathrm{C}$ & & This study \\
\hline D1-D5 & & This study \\
\hline E1-E9 & & This study \\
\hline $\mathrm{F}$ & & This study \\
\hline G1-G2 & & This study \\
\hline I1- I2 & & This study \\
\hline Liu_A1 & AB114069 & Liu et al. (2006) haplotype A1 \\
\hline Liu_B1 & AB007744 & Liu et al. (2006) haplotype B1 \\
\hline Liu_C1 & AB114070 & Liu et al. (2006) haplotype C1 \\
\hline Liu_D1 & AY588636 & Liu et al. (2006) haplotype D1 \\
\hline Liu_E1 & AB114076 & Liu et al. (2006) haplotype E1 \\
\hline Liu_F1 & AF512285 & Liu et al. (2006) haplotype F1 \\
\hline Liu_G1 & AF512288 & Liu et al. (2006) haplotype G1 \\
\hline Liu_H1 & D82904 & Liu et al. (2006) haplotype H1 \\
\hline Liu_I1 & AB009434 & Liu et al. (2006) haplotype I1 \\
\hline Oka_D6 & AB268535 & Oka et al. (2007) haplotype D6 \\
\hline Oka_G1 & AB268545 & Oka et al. (2007) haplotype G1 \\
\hline Oka_F1 & AB268543 & Oka et al. (2007) haplotype F1 \\
\hline
\end{tabular}

characteristics as reported by FAO (http://dad.fao.org/) and $\mathrm{Su}$ at al. (2004). The Tam Hoang and Luong Phuong Chinese breeds, which were included for comparison, were imported into Vietnam in 1995 and 2003, respectively, and have been kept as conservation flocks at the National Institute of Animal Sciences (NIAS) since that time. A total of 222 blood samples were collected in this study. On average, blood samples were taken from 20 randomly selected individuals among households per Vietnamese breed. Thereby, one male and one female were sampled per household. In addition, blood samples from 21 birds of each

Table 1. Polymorphic sites, haplotype and nucleotide diversity of chicken breeds

\begin{tabular}{llcccc}
\hline Breed & \multicolumn{1}{c}{ Study area } & $\begin{array}{c}\text { No. of } \\
\text { samples }\end{array}$ & $\begin{array}{c}\text { No. of } \\
\text { polymophic sites }\end{array}$ & $\begin{array}{c}\text { No. of } \\
\text { Haplotypes }\end{array}$ & $\begin{array}{c}\text { Haplotype } \\
\text { diversity }( \pm \text { SD) }\end{array}$ \\
\hline H’mong & Mai Son, Son La & 20 & 23 & 6 & $0.778 \pm 0.055$ \\
Mia & Duong Lam, Ha Tay & 20 & 10 & 7 & $0.737 \pm 0.094$ \\
Ri & Hoai Duc, Ha Tay & 20 & 22 & 12 & $0.911 \pm 0.045$ \\
Ho & Thuan Thanh, Bac Ninh & 20 & 8 & 4 & $0.615 \pm 0.105$ \\
Dong Tao & Khoai Chau, Hung Yen & 20 & 20 & 7 & $0.768 \pm 0.080$ \\
Te & Ba Vi, Ha Tay and NIAS & 20 & 14 & 5 & $0.716 \pm 0.086$ \\
Choi & Ninh Hoa, Khanh Hoa & 19 & 15 & 4 & $0.754 \pm 0.053$ \\
Ac & Tan an, Long An & 21 & 13 & 5 & $0.767 \pm 0.053$ \\
Tau Vang & & 20 & 24 & 13 & $0.942 \pm 0.034$ \\
Luong Phuong & NIAS & 21 & 19 & 8 & $0.852 \pm 0.053$ \\
Tam Hoang & & 21 & 11 & 37 & $0.705 \pm 0.095$ \\
Total & & 43 & 37 & $0.849 \pm 0.184$ \\
\hline
\end{tabular}


of the Chinese breeds were collected.

\section{mtDNA amplification and sequencing}

A fragment of $455 \mathrm{bp}$ from the mtDNA D-loop region was amplified using primers mtGlu-F (5'GGCTTGAAAAGCCATTGTTG-3') and mtGlu-R (5'CCCAAAAA GAGAAGGAACC-3'). Due to their circular nature, these primers are positioned at bases 16739-16775 (forward primer) and 649-668 (reverse primer) of the complete mtDNA sequence of domestic chickens (X52392, Desjardins and Morais, 1990). PCR amplifications and sequencing were done as described by Muchadeyi et al. (2008). To align DNA sequences, AlignIR software was used (LICOR Inc. Nebraska, USA). The list of sequences used in this study and the corresponding GenBank accession numbers are provided in Table S1.

\section{Statistical analysis}

The position and number of polymorphic sites as well as corresponding haplotypes were calculated using MEGA v. 3.1 (Kumar et al., 2004). To quantify differences between haplotypes, we constructed a median joining network following the algorithm of Bandelt et al. (1995) and using NETWORK v. 4.5.1.0 (http://www.fluxus-engineering.com/ sharenet. htm). In the network presented, all characters were unweighted (all 10). Furthermore, the parameter epsilon $(\varepsilon)$ specifies a weighted genetic distance, i.e. a tolerance up to which distances are not distinguished. Various networks were constructed by using different epsilon values ranging from zero to 20. There were no marked differences among the different networks except for a slight increase in the network connections where clades joined. The median network presented used an epsilon value of 5 . As reference, network analysis was used first to create a skeleton which was based on the most frequent haplotypes of the nine clades of Liu's network (Liu et al., 2006) and the three additional clades (D, G and F) of Oka et al. (2007). The sequences used for alignment consisted of $455 \mathrm{bp}$. This skeleton assigned clades to suggested regions of domestication in chickens, which were Yunnan and/or surrounding areas (Liu's clades A, B, F and G), South and Southwest China and/or surrounding areas and Southeast Asia (Liu's clade C, D, H, I and Oka's clade D, F, G), and the Indian subcontinent (Liu's clade E). Nomenclatures of the nine clades reported by Liu et al. (2006) were used as reference for the clade notation in this study. The haplotype diversities of breeds were computed using ARLEQUIN v. 3.1 (Excoffier et al., 2006). The haplotype diversity was estimated as follows (Nei, 1987):

$$
H=\frac{n}{n-1}\left(1-\sum_{i=1}^{k} p_{i}^{2}\right)
$$

Where: $n$ is the number of individuals, $k$ is number of haplotypes, $P_{i}$ is the frequency of the haplotype $i$.

To analyse if mtDNA clades also differed at the autosomal level, the data obtained from genotyping 29 microsatellite markers of these 222 individuals (Cuc at al., 2010) was used. These individuals were labelled according to their clade affiliation based on mtDNA sequences. The microsatellite genotyping data were used in the Bayesian model-based clustering as implemented in STRUCTURE v.2.3.1 to cluster individuals to a varying number of $\mathrm{K}$ clusters $(2 \leq K \leq 8)$ (Pritchard et al., 2000). For each $K$ value, 100 repeated runs were carried out. Comparisons of the 100 runs were done using SIMCOEFF (Rosenberg et al., 2002). Runs within each K-value showing a similarity coefficient of 0.95 and higher were considered as identical (Granevitze et al., 2009).

\section{RESULTS}

\section{Network profiles of the clades}

The distribution of clades is shown in Figure 1. Eight clades A to G, and I were found in the chicken breeds studied. Clades A, B and E were the most frequent whereas clades F, G and I consisted of a small number of individuals only. Within each of three clades A, B and E, the major haplotypes were A1, B1 and E1 encompassing 70\%, 77\% and $57 \%$ of each clade, respectively. The major haplotype of clade D was D1, of which $50 \%$ was observed in the Choi breed (Table S2).

\section{Breed distribution within clades}

The Vietnamese local chickens were found in all eight clades (Figure 1). The distribution of the Vietnamese breeds into clades was not related to their geographical distribution. The most frequent clades $\mathrm{A}$ and $\mathrm{B}$ included all nine Vietnamese breeds. A considerable proportion (14\%) of Vietnamese local chickens belonged to clade D while only a small number of Vietnamese chickens was assigned to the five remaining clades $(\mathrm{C}, \mathrm{E}, \mathrm{F}, \mathrm{G}$ and $\mathrm{I})$. In contrast, the majority (76\%) of Chinese chickens were found in clade $\mathrm{E}$ whereas no Chinese chickens were observed in clades D, G, $\mathrm{F}$ and $\mathrm{I}$.

\section{Within-population diversity}

Eight clades (A-G and I) were formed by 37 haplotypes, of which 25 were only found in the Vietnamese local breeds, six haplotypes were observed exclusively in the Chinese breeds, and the remaining six haplotypes were common (Table S3). The lowest haplotype diversity (0.62 \pm 0.105$)$ was estimated in the Ho breed, while the highest corresponding value $(0.942 \pm 0.034)$ was observed in the Tau Vang breed (Table 1). 


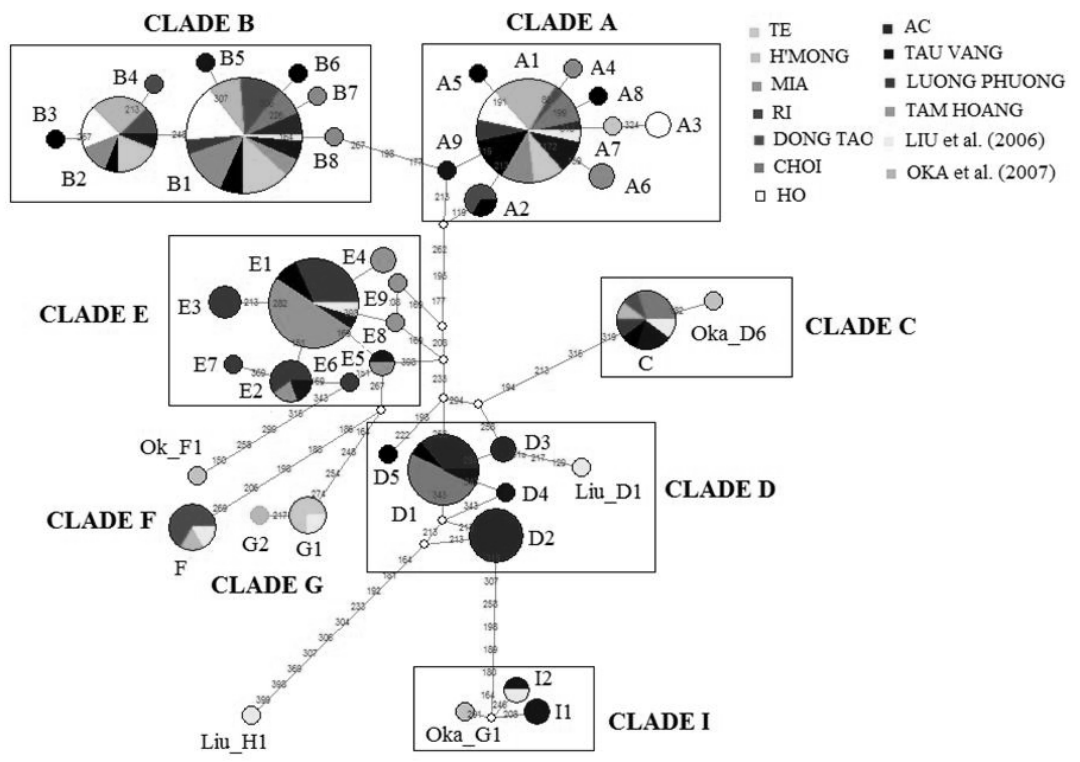

Figure 1. Median network profile of the mtDNA D-loop haplotypes observed in the current study. Data merged with sequences of major haplotypes reported by Liu et al. (2006) and Oka et al. (2007). The circle size corresponds to haplotype frequency, and the numbers on the line correspond to mutational positions connecting haplotypes. Empty circles are median vectors used in connecting indirectly related haplotypes.

Table S2. Distribution of mtDNA D-loop haplotypes in nine Vietnamese local chicken breeds and two Chinese breeds

\begin{tabular}{|c|c|c|c|c|c|c|c|c|c|c|c|c|}
\hline Hap. & H'mong & Mia & $\mathrm{Ri}$ & Ho & $\begin{array}{c}\text { Dong } \\
\text { Tao }\end{array}$ & $\mathrm{Te}$ & Choi & Ac & Tau Vang & $\begin{array}{l}\text { Luong } \\
\text { Phuong }\end{array}$ & Tam Hoang & Total \\
\hline$\overline{\mathrm{A} 1}$ & 6 & 3 & 4 & 3 & 1 & 3 & 3 & 1 & 3 & 2 & & 29 \\
\hline A2 & & & 1 & & 2 & & & & & & & 3 \\
\hline A3 & & & & 2 & & & & & & & & 2 \\
\hline A4 & & 2 & & & & & & & & & & 2 \\
\hline A5 & & & & & & 1 & & & & & & 1 \\
\hline A6 & & & 1 & & & & & & & & & 1 \\
\hline A7 & & 1 & & & & & & & & & & 1 \\
\hline A8 & & & 1 & & & & & & & & & 1 \\
\hline A9 & & & & & & & & & 1 & & & 1 \\
\hline B1 & 7 & 10 & 5 & 12 & 9 & 10 & 6 & 5 & 4 & 3 & 4 & 75 \\
\hline B2 & 4 & 2 & 1 & 3 & 2 & 3 & & & 1 & & & 16 \\
\hline B3 & & & 1 & & & & & & & & & 1 \\
\hline B4 & & & & & 1 & & & & & & & 1 \\
\hline B5 & & & & & & & & & 1 & & & 1 \\
\hline B6 & & & 1 & & & & & & & & & 1 \\
\hline B7 & & 1 & & & & & & & & & & 1 \\
\hline B8 & & 1 & & & & & & & & & & 1 \\
\hline C & 1 & & 1 & & 1 & & 3 & & 2 & 1 & & 9 \\
\hline D1 & & & 1 & & & & 7 & 5 & 1 & & & 14 \\
\hline D2 & & & & & & & & 8 & & & & 8 \\
\hline D3 & & & & & & & & 2 & & & & 2 \\
\hline D4 & & & & & & & & & 1 & & & 1 \\
\hline D5 & & & 1 & & & & & & & & & 1 \\
\hline E1 & & & 2 & & & & & & 1 & 7 & 11 & 21 \\
\hline E2 & & & & & & & & & 1 & 3 & 1 & 5 \\
\hline E3 & & & & & & & & & & 3 & & 3 \\
\hline E4 & & & & & & & & & & & 2 & 2 \\
\hline E5 & & & & & & & & & 1 & & 1 & 2 \\
\hline E6 & & & & & & & & & & 1 & & 1 \\
\hline E7 & & & & & & & & & & 1 & & 1 \\
\hline E8 & & & & & & & & & & & 1 & 1 \\
\hline E9 & & & & & & & & & & & 1 & 1 \\
\hline F & 1 & & & & 4 & & & & & & & 5 \\
\hline G1 & & & & & & 3 & & & & & & 3 \\
\hline G2 & 1 & & & & & & & & & & & 1 \\
\hline I1 & & & & & & & & & 2 & & & 1 \\
\hline I2 & & & & & & & & & 1 & & & 1 \\
\hline Total & 20 & 20 & 20 & 20 & 20 & 20 & 19 & 21 & 20 & 21 & 21 & 222 \\
\hline
\end{tabular}


Table S3. Variable sites for 37 mtDNA haplotypes observed in 11 chicken populations

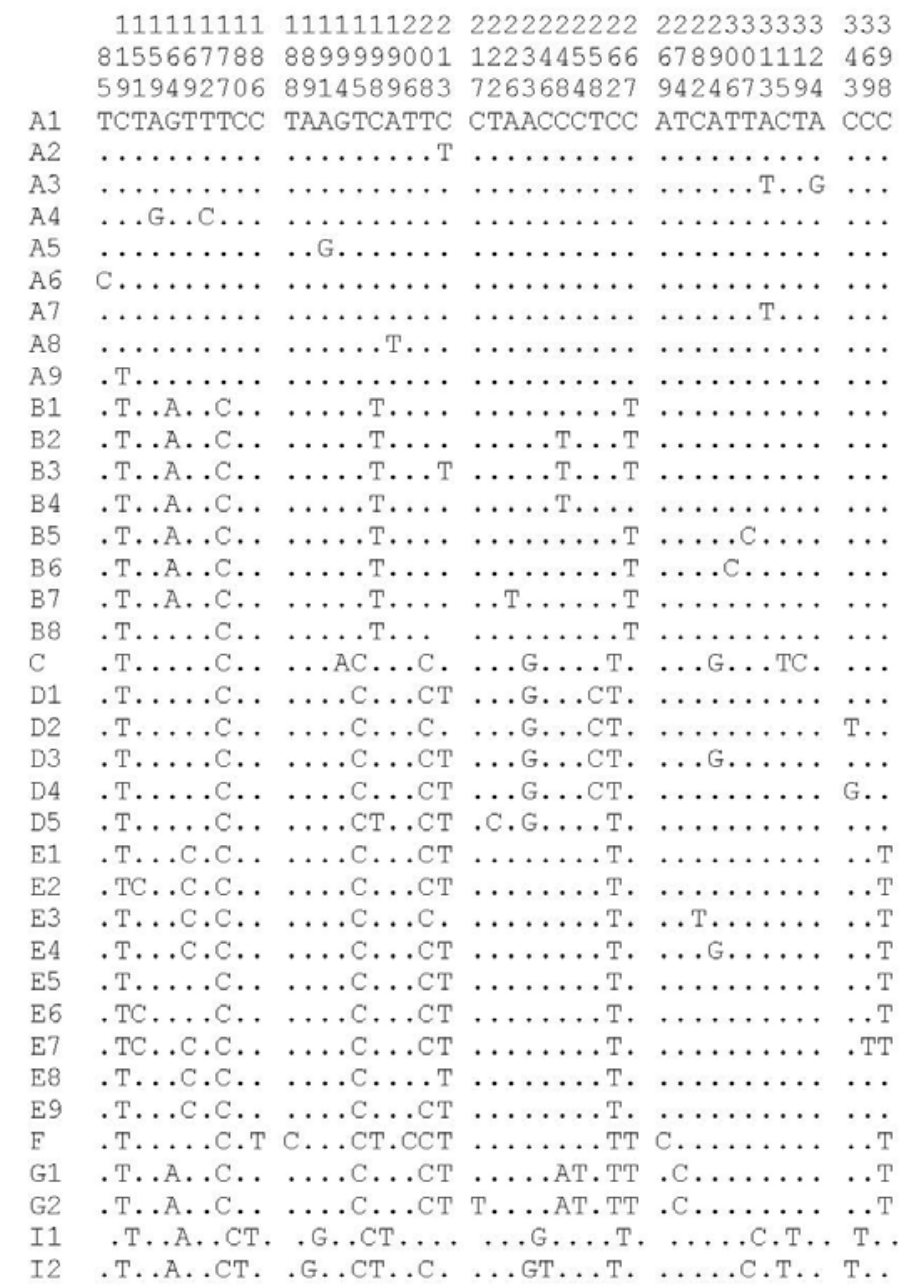

Dots indicate nucleotide positions identical to those of Haplotype A1

Numbers at the top refer to variable sites and correspond to the nucleotide positions of Haplotype A1.

\section{Relationship between mtDNA and autosomal genetic structure}

The results of the STRUCTURE analysis from $\mathrm{K}=2$ to $\mathrm{K}=6$ are shown in Figure 2. The repeatability, i.e., the number of runs giving a result with similarity coefficient 0.95 , varied from 34 to 100 from $K=2$ to $K=6$, while no identical runs were found at $\mathrm{K}=7$ and 8 (data not shown). For all $\mathrm{K}$ values, the mtDNA defined clade $\mathrm{E}$ was found as a pure cluster at the autosomal level while the other seven mtDNA defined clades were mixed to different degrees (Figure 2).

\section{DISCUSSION}

The majority of the Vietnamese local chickens carried mtDNA haplotypes that clustered in clades A and B. Based on the skeleton of supposed regions of domestication, this finding suggests the existence of two maternal lineages

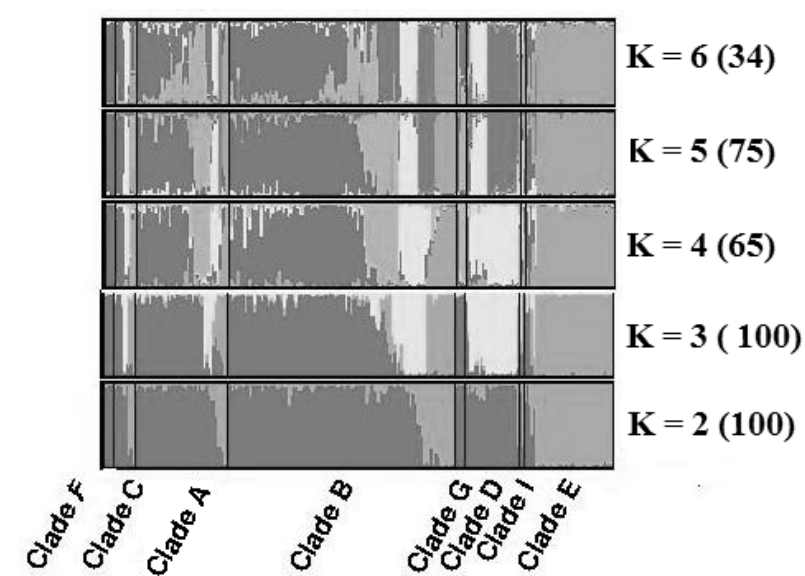

Figure 2. STRUCTURE based clustering using microsatellite genotypes of chicken groups assigned to eight mtDNA clades. Individuals are labelled according to their clade affiliation based on mtDNA sequences. Number in parenthesis is the number of runs giving an identical result (similarity coefficient $\geq 0.95$ ). 
dominating in the Vietnamese local chickens, which presumably originated from Yunnan and surrounding regions in China (Liu et al., 2006). Fourteen percent of Vietnamese chickens were found in clade D indicating that this clade also contributed considerably to the Vietnamese local chickens. Liu et al. (2006) and Oka et al. (2007) suggested that this clade has its root in Southeast, South and Southwest China and/or surrounding areas (i.e. Vietnam, Burma, Thailand, and India). This finding would be in agreement with historical records of human immigration from southern China to Vietnam. Yüeh people are inhabitants in the Southeastern coast of China and are the ancestors of the Cantonese, i.e., Guangzhou and Guangxi Southern Chinese people. By the 3rd century B.C., Yüeh people emigrated from Southern China to the Red River Delta of Vietnam and mixed with the indigenous Van Lang Vietnamese population (Taylor, 1983). Additionally, Southern Chinese people from Yunnan, Guangzhou and Guangxi Provinces arrived in the North of Vietnam and moved to the South from the 17th to the 19th century A.C. (Nyiri and Saveliev, 2002). Descriptions of immigration always state that people of a family moved together with their animals which could result in the introduction of chickens from Southern China into the North and South of Vietnam. While Yunnan, South and Southwest China might be seen as regions of origin of the Vietnamese chicken breeds, the majority of individuals of Chinese breeds in this study were not assigned to these maternal lineages. This finding indicates that two Chinese breeds kept at NIAS do not represent the breeds of Yunnan, South and Southwest China.

The high proportion of haplotype D1 found in the Choi chickens is in agreement with findings of Liu et al. (2006), who reported that clade D mainly consisted of game birds. In contrast, the clustering of the remaining Choi chickens in clades A and B is consistent with the study of Oka et al. (2007) who found game birds assigned to their clades B and E. Consequently, our findings suggest that the game breed Choi is a mixture of multiple maternal lineages.

A small number of Vietnamese chickens distributed in clades C, F, G and I indicates that these clades have little contribution to Vietnamese chickens. A small portion (2\%) of Vietnamese local chickens was observed in clade E, originating from the Indian subcontinent (Liu et al., 2006), which otherwise harboured mainly the Chinese chickens studied. Vietnamese local chickens in this clade included the Ri and Tau Vang breeds. This observation may indicate a possible exchange of genetic material between the $\mathrm{Ri}$ and Chinese chickens due to the wide distribution of the $\mathrm{Ri}$ chickens, while the Chinese origin of the Tau Vang breed (Linh, 2005) is known and explains the distribution of this breed in both Vietnamese and Chinese clades. This finding is also in agreement with analysis at the autosomal level in which the Tau Vang breed showed clear admixture between the Chinese and Vietnamese gene pools (Cuc et al., 2010).

Although the majority of the Vietnamese chicken breeds in this study were assigned to clade $\mathrm{A}$ and $\mathrm{B}$, the Vietnamese breeds were found to be highly polymorphic in the mtDNA D-loop region. Estimates of haplotype diversity ranged from 0.62 to 0.94 in this study and were higher than reported previously. Muchadeyi et al. (2008) found the haplotype diversity ranged from 0.61 to 0.73 and from 0.27 to 0.78 in Zimbabwean chickens and purebred lines, respectively. Liu et al. (2004) pointed out three of 12 Chinese breeds with only one haplotype. The high degree of diversity of the Vietnamese breeds is in agreement with previous reports showing high diversity at the autosomal level by analysing microsatellites. (Granevitze et al., 2007; Berthouly et al., 2009; Cuc et al., 2010).

Comparing results of phylogenetic relationship using mtDNA polymorphism and autosomal microsatellites, it becomes obvious that the Chinese breeds cluster together and are separated from the Vietnamese local breeds using both genetic marker systems, indicating a clear genetic differentiation between them and the Vietnamese breeds. Although Tieu et al. (2008) assumed that the Chinese chickens from NIAS have introgressed into local Vietnamese chickens, our results do not support this hypothesis, except for the Ri and Tau Vang chickens. In contrast to microsatellite analyses, which found that clustering of Vietnamese local breeds has a relationship to their geographical distribution (Cuc et al., 2010), no substructuring was found between the Vietnamese local breeds at the mtDNA level. The different results obtained with both types of markers could be due to the different mode of inheritance. Unlike autosomal genetic markers, mtDNA transferred from mother to offspring is not rearranged due to recombination and is less affected by gene drift (Johnson et al., 2003). In addition, mtDNA has a lower mutation rate than microsatellite as argued by Feulner et al. (2004).

In conclusion, mtDNA analysis done in this study suggests that Vietnamese breeds are of multiple maternal origins, and lineages are distributed across the country. Human immigration from the North to the South in ancient times could have resulted in the wide distribution of these lineages in both parts of Vietnam. As the relationship between Vietnamese breeds and Red Jungle fowl is not clear yet, efforts are needed to include local wild chicken populations from Vietnam into future research. In terms of Chinese breeds, results showed that the studied breeds are not related to Vietnamese breeds as revealed at both autosomal and mitochondrial levels expect for $\mathrm{Ri}$ and Tau Vang. Therefore, efforts to conserve genetic diversity of Vietnamese chickens should focus on local populations which are distinguishable from the Chinese chicken gene pool. 


\section{ACKNOWLEDGMENTS}

The authors express sincere thanks to the Vietnamese farmers for providing chicken samples, to A. Weigend and A. Flörke, Institute of Farm Animal Genetics at Mariensee, for technical assistance, as well as to Prof. Dr. Clemens B.A. Wollny, Faculty of Life Sciences, University of Applied Sciences Bingen, Germany and Prof. Dr. Hoang Van Tieu, National Institute of Animal Husbandry, Hanoi, Vietnam, for project initiative. N.T.K. Cuc had a stipend from German Academic Exchange Service (DAAD), and the project was funded by the German Federal Ministry of Education and Research (BMBF).

\section{REFERENCES}

Bandelt, H. J., P. Forster, B. C. Sykes and M. B. Richards. 1995. Mitochondrial portraits of human populations using median networks. Genetics 141:743-753.

Berthouly, C., G. Leroy, T. N. Van, H. H. Thanh, B. Bed'Hom, B. T. Nguyen, C. C. Vu, F. Monicat, M. Tixier-Boichard, E. Verrier, J. Maillard and X. Rognon. 2009. Genetic analysis of local Vietnamese chickens provides evidence of gene flow from wild to domestic populations. BMC Genet. 10:1.

Cuc, N. T. K., H. Simianer, H. Eding, H. V. Tieu, V. C. Cuong, C. B. A. Wollny, L. F. Groeneveld and S. Weigend. 2010. Assessing genetic diversity of Vietnamese local chicken breeds using microsatellites. Anim. Genet. (in press).

Desjardins, P. and R. Morais. 1990. Sequence and gene organisation of the chicken mitochondrial genome: a novel gene order in higher vertebrates. J. Mol. Biol. 212:599-634.

Eriksson, J., G. Larson, U. Gunnarsson, B. Bed'hom, M. TixierBoichard, L. Strömstedt, D. Wright, A. Jungerius, A. Vereijken, E. Randi, P. Jensen and L. Andersson. 2008. Identification of the yellow skin gene reveals a hybrid origin of the domestic chicken. PLoS Genet. 4: e1000010.

Excoffier, L., G. Laval and S. Schneider. 2006. arlequin Version 3.01: An integrated software package for population genetics data analysis.

Feulner, P. G. D., W. Bielfeldt, F. E. Zachos, J. Bradvarovic, I. Eckert and G. B. Hartl. 2004. Mitochondrial DNA and microsatellite analyses of the genetic status of the presumed subspecies Cervus elaphus montanus (Carpathian red deer). Heredity 93:299-306.

Fumihito, A., T. Miyake, M. Takada, R. Shingu, T. Endo, T. Gojobori, N. Kondo and S. Ohno. 1996. Monophyletic origin and unique dispersal patterns of domestic fowls. Proc. Natl. Acad. Sci. USA 93: 6792-6795

Granevitze, Z., J. Hillel, G. H. Chen, N. T. K. Cuc, M. Feldman, H. Eding and S. Weigend. 2007. Genetic diversity within chicken populations from different continents and management histories. Anim. Genet. 38:576-583.
GSO (General Statistics Office of Vietnam). 2008. Statistical yearbook of Vietnam, Statistic Publisher, Hanoi, Vietnam.

Harpending, H. C., M. A. Batzer, M. Gurven, L. B. Jorde, A. R. Rogers and S. T. Sherry. 1998. Genetic traces of ancient demography. Proc. Natl. Acad. Sci. USA 95:1961-1967.

Johnson, J. A., J. F. Toepfer and P. O. Dunn. 2003. Contrasting patterns of mitochondrial and microsatellite population structure fragmented populations of greater prairie-chickens. Mol. Ecol. 12:3335-3347.

Kanginakudru, S., M. Metta, R. D. Jakati and J. Nagaraju. 2008. Genetic evidence from Indian red jungle fowl corroborates multiple domestication of modern day chicken. BMC Evol. Biol. 8:174.

Kumar, S., K. Tamura and M. Nei. 2004. Mega3: integrated software for molecular evolutionary genetics analysis and sequence alignment. Brief. Bioinformatics 5:150-163.

Linh, V. T. 2005. The world of rare chickens in Vietnam. Vietbao Newspaper (issued on February 11st ), Vietnam.

Liu, Y. P., G. S. Wu, Y. G. Yao, Y. W. Miao, G. Luikart, M. Baig, A. Beja-Pereira, Z. L. Ding, M. G. Palanichamy and Y. P. Zhang. 2006. Multiple maternal origins of chickens: out of the Asian jungles. Mol. Phylogenet. Evol. 38:112-119.

Liu, Z. G., C. Z. Lei, J. Luo, C. Ding, G. H. Chen, H. Chang, K. H. Wang, X. X. Liu , X. Y. Zhang, X. J. Xiao and S. L. Wu. 2004. Genetic variability of mtDNA sequences in Chinese native chicken breeds. Asian-Aust. J. Anim. Sci. 17:903-907.

Muchadeyi, F. C., H. Eding, H. Simianer, C. B. A. Wollny, E. Groeneveld and S. Weigend. 2008. Mitochondrial DNA D-loop sequences suggest a Southeast Asian and Indian origin of Zimbabwean village chickens. Anim. Genet. 39:615-622.

Nei, M. 1987. Molecular Evolutionary Genetics Columbia University Press: New York, USA.

Nyiri, P. and I. Saveliev. 2002. Globalizing Chinese migration: Trends in Europe and Asia research in migration and ethnic relations series. Ashgate Publisher, Aldershot, United Kingdom.

Oka, T., Y. Ino, K. Nomura, S. Kawashima, T. Kuwayama, H. Hanada, T. Amano, M. Takada, N. Takahata, Y. Hayashi and F. Akishinonomiya. 2007. Analysis of mtDNA sequences shows Japanese native chickens have multiple origins. Anim. Genet. 38:287-293.

Pritchard, J. K., M. Stephens and P. Donnerly. 2000. Inference of population structure using multilocus genotype data. Genetics 155:945-959.

Reynolds, J., B. S. Weir, C. C. Cockerham. 1983. Estimation of the coancestry coefficient: Basis for a short-term genetic distance. Genetics 105:767-779.

Su, V. V., N. V. Thien, D. T. Nhiem, V. L. Ly, N. V. Hai and H. V. Tieu. 2004. Atlas of farm animal breeds in Vietnam. Agricultural Publishers, Hanoi, Vietnam.

Taylor, K. W. 1983. The birth of Vietnam. Unversity of California press, London, United Kingdom.

Tieu, H. V., L. V. Ly, L. V. Sat and V. V. Su. 2008. Vietnamese livestock genetic resources conservation and exploitation from 1990 to 2007. Vietnamese J. Anim. Sci. Technol. special volume: $1-10$. 